\title{
Findings From aCGH in Patients With Congenital Diaphragmatic Hernia (CDH): A Possible Locus for Fryns Syndrome
}

\author{
S. Kantarci ${ }^{1}$, D. Casavant ${ }^{1}$, C. Prada ${ }^{2}$, M. Russell ${ }^{1}$, J. Byrne ${ }^{3}$, L. Wilkins Haug ${ }^{4}, \mathbf{R}$. \\ Jennings $^{5}$, S. Manning ${ }^{6}$, T.K. Boyd ${ }^{7}$, J.P. Fryns ${ }^{8}$, L.B. Holmes ${ }^{9}$, P.K. Donahoe ${ }^{1}$, C. Lee ${ }^{10}$, \\ V. Kimonis ${ }^{2}$, and B.R. Pober $5,9,{ }^{*}$ \\ ${ }^{1}$ Pediatric Surgical Research Laboratories, MassGeneral Hospital for Children, Harvard Medical \\ School, Boston, Massachusetts \\ 2Division of Genetics, Children's Hospital, Harvard Medical School, Boston, Massachusetts \\ ${ }^{3}$ Department of Obstetrics and Gynecology, University of Utah, Salt Lake City, Utah \\ ${ }^{4}$ Department of Obstetrics and Gynecology, Brigham \& Women's Hospital, Harvard Medical School, \\ Boston, Massachusetts \\ ${ }^{5}$ Department of Surgery, Children's Hospital, Harvard Medical School, Boston, Massachusetts \\ ${ }^{6}$ Division of Newborn Medicine, Children's Hospital, Harvard Medical School, Boston, \\ Massachusetts \\ ${ }^{7}$ Department of Pathology, Children's Hospital, Harvard Medical School, Boston, Massachusetts \\ ${ }^{8}$ Department of Genetics, University Hospital of Leuven, Leuven, Belgium \\ ${ }^{9}$ Genetics and Teratology, MassGeneral Hospital for Children, Harvard Medical School, Boston, \\ Massachusetts \\ ${ }^{10}$ Department of Pathology, Brigham and Women's Hospital, Harvard Medical School, Boston, \\ Massachusetts
}

\begin{abstract}
Congenital diaphragmatic hernia $(\mathrm{CDH})$ is a common and often devastating birth defect that can occur in isolation or as part of a malformation complex. Considerable progress is being made in the identification of genetic causes of $\mathrm{CDH}$. We applied array-based comparative genomic hybridization $(\mathrm{aCGH})$ of $\sim 1 \mathrm{Mb}$ resolution to $29 \mathrm{CDH}$ patients with prior normal karyotypes who had been recruited into our multi-site study. One patient, clinically diagnosed with Fryns syndrome, demonstrated a de novo $5 \mathrm{Mb}$ deletion at chromosome region 1q41-q42.12 that was confirmed by FISH. Given prior reports of $\mathrm{CDH}$ in association with cytogenetic abnormalities in this region, we propose that this represents a locus for Fryns syndrome, a Fryns syndrome phenocopy, or CDH.
\end{abstract}

\section{Keywords}

congenital diaphragmatic hernia; Fryns syndrome; chromosome 1q41-q42.12 deletion; array-based comparative genomic hybridization (aCGH); FISH

"Correspondence to: Dr. B.R. Pober, Children's Hospital Boston, 300 Longwood Ave., Fegan 325, Boston 02115, MA.

Barbara.pober@childrens.harvard.edu or bpober@partners.org.

S. Kantarci and D. Casavant are the first authors who contributed equally to this work.

C. Lee, V. Kimonis, and B.R. Pober are the senior authors who contributed equally to this work. 


\section{Introduction}

Congenital diaphragmatic hernia $(\mathrm{CDH})$ refers to a group of common developmental defects in the formation of the diaphragm [Tibboel and Gaag, 1996] found in as many as 1/3,000 live births. The most common type of $\mathrm{CDH}$ affects the posterolateral region of the diaphragm and is referred to as a Bochdalek hernia. Just over half of patients have $\mathrm{CDH}$ as their only malformation. The remainder have additional anomalies either as part of non-syndromic associations, chromosome abnormalities, or recognized syndromes [Torfs et al., 1992; Robert et al., 1997; Tonks et al., 2004; Pober et al., 2005; Slavotinek, 2005]. The etiology for the majority of $\mathrm{CDH}$ cases remains unknown, but evidence is accumulating from the study of model organisms as well as human cases, that genetic mutations are involved in their pathogenesis [Devriendt et al., 1995; Liu et al., 2003; Yuan et al., 2003; Reardon et al., 2004; Ackerman et al., 2005]. The most common autosomal recessive disorder associated with CDH, Fryns syndrome [OMIM \#229850], currently has no identified genetic or biochemical marker [Fryns et al., 1979; Fryns, 1987; Slavotinek, 2004]. This multiple anomaly syndrome is, therefore, diagnosed using clinical criteria, resulting in a broad phenotypic array of cases being labeled with Fryns syndrome [Ramsing et al., 2000; Arnold et al., 2003].

As part of our ongoing search to identify genetic causes of $\mathrm{CDH}$, we have used array-based comparative genomic hybridization (aCGH) to screen patients with either isolated or complex $\mathrm{CDH}$. Once genomic imbalances have been found by this methodology, we anticipate that loci and even candidate genes important for diaphragm development will be identified.

\section{Patients and Methods}

\section{Patients}

Probands with CDH were recruited through our multi-site study "Gene Mutations and Rescue in Human Congenital Diaphragmatic Hernia." Participants come from several sources: patients receiving clinical care at either MassGeneral Hospital for Children or Children's Hospital, Boston; self-referred families through CHERUBS [The Association of Congenital Diaphragmatic Hernia Research, Advocacy, and Support, a nonprofit parent-support group]; and referrals from national and international colleagues. Information collected on each person with $\mathrm{CDH}$ came from a medical record review, construction of a family pedigree, and a physical examination (whenever possible) by the study geneticists. Patients were classified as having isolated $\mathrm{CDH}$ (CDH with no additional major malformations or evidence of a syndrome) or complex $\mathrm{CDH}(\mathrm{CDH}$ occurring in association with a chromosome abnormality or with additional birth defects, but not as part of a recognized syndrome). Between 10-20\% of the cases in each of these categories were studied by aCGH. Parents and siblings were also recruited into the study. Samples for genomic DNA, metaphase chromosome preparations, and cell-line establishment were collected from the proband and as many first-degree relatives as possible. If a patient with $\mathrm{CDH}$ had died, autopsy material was the only potential source of DNA. The Institutional Review Boards at MassGeneral Hospital for Children and Children's Hospital, Boston reviewed and approved this study each year.

\section{Genomic DNA}

Genomic DNA was isolated from either blood samples or cultured fibroblasts using the Puregene DNA Purification Kit (Gentra Systems, Minneapolis, MN) according to the manufacturer's recommendations. DNA amounts were quantified using the NanoDrop NDSpectrophotometer (NanoDrop Technologies, Wilmington, DE). 
We used a genome-wide screening method, array-based comparative genomic hybridization (aCGH), to identify DNA copy number changes in a total of 29 cases. aCGH studies were performed using the commercially available Spectral Genomechip ${ }^{\mathrm{TM}}$ V1.2 arrays (Spectral Genomics, Inc., Houston, TX). This chip contains 2,632 bacterial artificial chromosome (BAC) clones with $\sim 1 \mathrm{Mb}$ resolution spotted in duplicate on a glass slide. Two micrograms of genomic DNA were fragmented by sonication, purified (DNA Clean \& Concentrator-25, Zymo Research, Orange, CA), and labeled by random priming (BioPrime Labeling Kit, Invitrogen, Carlsbad, CA). Dye-reversal experiments were performed for each sample to minimize false positive results. The labeled DNAs were denatured and applied to two separate array slides according to the manufacturer's protocols. DNA hybridization and post-hybridization washes were done as recommended. An Axon GenePix 4000B microarray scanner was used for scanning and the $\mathrm{Cy} 3$ and $\mathrm{Cy} 5$ florescence intensities at each DNA spot were quantified by GenePix Pro 4.0 Microarray Image Analysis software. Resulting images were analyzed with SpectralWare 2.0 (Spectral Genomics, Inc.) for preparation of chromosome-specific ratio plots. Spots with low signal-to-noise (background) ratios were excluded. A pooled reference source (Promega, Inc., Madison, WI) was used in sex-matched aCGH experiments. BAC clones showing large-scale copy number variations (CNVs) were detected [Iafrate et al., 2004] and these individual isolated BAC clones were excluded from further analysis (many of which were previously identified as being CNVs-http://projects.tcag.ca/variation/).

\section{FISH}

Specific BAC clones for FISH confirmation of aCGH findings were selected using the UCSC genome browser (http://genome.ucsc.edu) and were obtained from the BAC/PAC Resource (Children's Hospital, Oakland, CA). The chromosome 1 probe, DXZ1 from Vysis, Inc. (Downers Grove, IL), specifically hybridizes to $1 \mathrm{p} 11-\mathrm{q} 11$ and was used as a control probe. BAC DNA was isolated using the Mini DNA plasmid kit (Qiagen, Valencia, CA) according to the manufacturer's instructions. Probes were labeled by nick translation with nucleotides conjugated with SpectrumGreen-11-dUTP and SpectrumOrange-11-dUTP (Vysis, Abbott Laboratories, Abbott Park, IL) as recommended by the manufacturer. FISH was performed on metaphase chromosome preparations and interphase nuclei using standard hybridization conditions. All clone positions were confirmed by FISH mapping onto normal chromosome spreads. Signals were examined using an Olympus AX70 fluorescent microscope equipped with a CCD camera (Photometrics KAF 1400), and image analyses were performed with Genus software (Applied Imaging, San Jose, CA).

\section{Results}

Twenty-nine chromosomally normal patients with $\mathrm{CDH}$ were studied using the Spectral $1 \mathrm{Mb}$ GenomeChip ${ }^{\mathrm{TM}}$ V1.2 arrays. Eleven cases were clinically classified as having isolated CDH, while 18 were classified as having complex $\mathrm{CDH}$. Among those with complex $\mathrm{CDH}$, aCGH demonstrated an abnormality in a single case, a de novo deletion involving chromosome regions 1q41-q42.12. This case was the Twin B product of a dichorionic diamniotic gestation born at $371 / 7$ weeks by cesarian for transverse breech presentation to a 31-year-old gravida 3 , para 2 woman. Amniocentesis revealed a normal 46,XX karyotype in each twin. Apgar scores for Twin B were 1/1, and the immediate neonatal course was complicated by a difficult endotracheal intubation and an emergency laparotomy for evacuation of a hemoperitoneum. Despite intensive efforts, Twin B died at $1 \mathrm{hr}$ of age. Twin A had a normal physical and developmental examination in the newborn period and again at 3 months of age. Of note during the newborn examination, Twin A's fingernails and toenails were normal in size and larger than those found in Twin B (described below). Twin zygosity could not be established based on placental membranes. 
On postmortem examination (Fig. 1a-f), Twin B's weight was $1.81 \mathrm{~kg}(<10$ th centile), crownheel length, $45 \mathrm{~cm}$ (normal for gestational age: $44.5 \pm 7.0 \mathrm{~cm}$ ), and head circumference, 30.7 $\mathrm{cm}(<5$ th centile). The skull and face were remarkable for slightly coarse features, hypertelorism (inner canthal distance equaling $2.3 \mathrm{~cm}$ ), a boxy forehead, and large fontanelles (anterior and posterior fontanelles measuring $6 \times 4 \mathrm{~cm}$ and $3.5 \times 8 \mathrm{~cm}$, respectively). Additional distinctive craniofacial findings included a depressed nasal bridge and broad nasal tip, anteverted nares, a short philtrum, a tented upper lip, a midline cleft of the soft palate, and normally formed but slightly low set ears. The extremities showed mild upper arm shortening, positional finger flexion, talipes equinovarus, and moderate hypoplasia of fingernails and toenails. Internal examination revealed a large left Bochdalek diaphragm hernia, mild right diaphragmatic eventration, and bilateral pulmonary hypoplasia (with left and right lungs weighing $1.2 \mathrm{gm}$ and $9.0 \mathrm{gm}$, respectively; normal combined lung weights for gestational age $=35.0 \pm 10.8 \mathrm{gm})$. The heart was anatomically unremarkable except for a small probe patent muscular ventricular septal defect. The mucosa of the false and true vocal cords was abraded bilaterally, presumably secondary to the traumatic intubation. However, there was abnormal fullness of the supraglottic larynx compared to an age-matched autopsy control, suggesting partial supraglottic and glottic luminal stenosis. Gross and microscopic examination of the kidneys and uterus were both normal.

Postnatal karyotype (450 band level, Genzyme Genetics) on a skin biopsy taken at the time of autopsy confirmed the normal amniocentesis results.

aCGH performed on DNA extracted from the proband's fibroblasts demonstrated the loss of three consecutive BAC clones, RP11-124J24 (1q41), RP11-239E10 (1q41-1q42.11), and RP5-1090A23 (1q42.12). Non-deleted flanking probes RP11-553F10 and RP11-27504, which map to 1q41 and 1q42.13, respectively, suggested that the deletion is on the order of 5 million base pairs (Fig. 2a). aCGH identified no abnormalities in either parent (Fig. 2b,c). The deletion was confirmed independently in a CLIA-certified laboratory, Signature Genomics, Spokane, WA, using the SignatureChip ${ }^{\mathrm{TM}}$ array and FISH (data not shown).

FISH analysis of interphase preparations from Twin B was abnormal with deletion of the following probes: RP11-124J24 (1q41), RP11-239E10 (1q41-1q42.11), and RP5-1090A23 (1q42.12). Deletion of RP11-124J24 (green) is demonstrated in the proband, while both copies of the DXZ1 control probe (red) mapping to the centromere of chromosome 1 are evident (Fig. 3 ). We confirmed diploid copies of flanking probes in all three subjects; additionally, each parent was diploid for both the chromosome 1q41-1q42.12 and the chromosome 1 centromere probes (data not shown).

Among the 11 patients with isolated $\mathrm{CDH}$, none had an abnormality demonstrated by aCGH. All of the patients in this series had at least one of the previously reported aCGH-CNVs. Additionally, one patient had an approximate 3-Mb duplication of two consecutive BAC clones, AC108710.3 and RP11-91M15, at chromosome 3q11.2 (data not shown). The phenotypically normal mother of this patient demonstrated duplication of the same BACs on aCGH, suggesting this is an inherited CNV.

\section{Discussion}

aCGH is a powerful tool for detecting genomic imbalances at a high resolution and has been used increasingly to uncover abnormalities in patients with structural birth defects, dysmorphology, and learning disabilities or mental retardation. Evaluations of such patients, who had prior normal karyotypes, demonstrate a 10-15\% frequency of de novo deletions or duplications [Kirchhoff et al., 2001; Shaw-Smith et al., 2004; Le Caignec et al., 2005].

Recently, the application of this technology made it possible to identify the genetic basis of 
CHARGE syndrome, a well recognized multiple malformation disorder [Vissers et al., 2004]. In light of the increasing evidence that genetic abnormalities play a role in the causation of CDH (summarized in [Pober et al., 2005]), we chose to screen the participants in our ongoing $\mathrm{CDH}$ study using an aCGH platform designed to detect genomic imbalances greater than $\sim 1$ $\mathrm{Mb}$ resolution (Spectral Genomics, Inc.).

Among 11 patients classified as having isolated $\mathrm{CDH}$, no pathological abnormalities are suggested using aCGH of this resolution. However, 1 of our 18 cases with complex CDH, clinically diagnosed as having Fryns syndrome (MIM\# 229850), has a de novo 5Mb deletion at chromosome region 1q41-q42.12. This patient appears to have "classic" Fryns syndrome by manifesting almost all the common features, including the characteristic coarse facial appearance. Fryns syndrome is a multiple malformation disorder of unknown etiology. Based on case reports of parental consanguinity and of sibling recurrences, it is considered an autosomal recessive disorder [Meinecke and Fryns, 1985; Fryns, 1987; Moerman et al., 1988] and may be the most common monogenic syndrome associated with CDH. Frequent findings in Fryns syndrome include congenital abnormality of the diaphragm, coarse facial features, distal digital hypoplasia of the nails and/or terminal phalanges, pulmonary hypoplasia, genitourinary anomalies, cardiovascular malformations, and orofacial clefting [Fryns et al., 1979; Slavotinek, 2004]. Polyhydramnios is present in over half of patients. No standardized diagnostic criteria currently exist for Fryns syndrome. However, clinical guidelines have recently been proposed for dividing cases into narrowly defined (e.g., "classic"), broadly defined, or atypical Fryns syndrome [Lin et al., in press]. Additionally, criteria could be developed to objectify the extent of nail and distal phalangeal hypoplasia that might aid in the clinical diagnosis of Fryns syndrome, as has been done in children exposed to anticonvulsants [Lu et al., 2000].

Two findings were present in our Fryns syndrome patient, which merit further comment. Her nail hypoplasia was only moderately severe, though significant in comparison to her twin sister. Second, enlarged fontanelles are not mentioned in most previous descriptions of Fryns syndrome. It is possible that this finding has been overlooked in critically ill newborns, since review of photographs from a few case reports suggests the presence of enlarged fontanelles not described in the clinical synopsis [Schwyzer et al., 1987]. It is also possible that Fryns syndrome encompasses a mild skeletal dysplasia, as some patients diagnosed with Fryns syndrome have limb shortening [Kershisnik et al., 1991; Tsukahara et al., 1995; Slavotinek et al., 2005b]. Perhaps, enlarged fontanelles and limb shortening are both manifestations of an underlying mild skeletal dysplasia; however, these abnormalities are not frequently reported together in the same case. Finally, one of the authors (JPF) has observed enlarged fontanelles in unpublished cases with Fryns syndrome.

aCGH at this level of resolution can reveal CNVs scattered through out the genome, in addition to pathological genomic imbalances [Iafrate et al., 2004; Sebat et al., 2004]. Not surprisingly, we identified previously reported CNVs in all 29 patients studied. However, one patient demonstrated a previously unreported $\sim 3 \mathrm{Mb}$ duplication of two consecutive BAC clones at chromosome 3q11.2 which was also present in the normal mother. The clinical significance of CNVs is currently unknown. Whether or not a distinctive pattern exists in cases with $\mathrm{CDH}$, compared to healthy individuals, has yet to be determined.

The finding of a chromosome microdeletion in a patient with a presumed autosomal recessive disorder is consistent with several different causal mechanisms. Perhaps, Fryns syndrome is caused by de novo autosomal dominant mutations rather than autosomal recessive mutations. Accordingly, sibling recurrences could be due to either low-level somatic or gonadal mosiacism in one of the parents. Other disorders previously thought to follow an autosomal recessive pattern of inheritance now known to be due to dominant mutations include 
campomelic dysplasia [OMIM \#114290] [Lynch et al., 1993], osteogenesis imperfecta type II [OMIM \#166210] [Cohn et al., 1990], and one form of Larsen syndrome [OMIM\#150250] [Petrella et al., 1993]. Alternatively, our patient may have autosomal recessive Fryns syndrome, with deletion of the causal gene in the 1q41-q42.12 critical interval, combined with a mutation in the causal gene on the other chromosome 1 homolog. Finally, it is possible that our patient does not have Fryns syndrome, but rather a phenocopy caused by the de novo deletion, indicating genetic heterogeneity for this phenotype.

We propose that the chromosome $1 \mathrm{q} 41-\mathrm{q} 42.12$ locus is likely to house one or more genes required for normal diaphragm development. There are three publications reporting cases of $\mathrm{CDH}$, plus other malformations (Table I), associated with cytogenetic rearrangements at or near this region [Youssoufian et al., 1988;Smith et al., 1994;Rogers et al., 1995]. Further evidence implicating the importance of this region is twofold: (a) our recent identification of yet an additional patient, a 5-month-old deceased from complications of diaphragmatic eventration, who had a cytogenetically visible deletion at 1q41-q42.13; and (b) mention of one Fryns syndrome patient detected by HumArray 3.1 BAC aCGH to have a 1q41-1q42.2 deletion [Slavotinek et al., 2005a]. Notably, the patients with visible 1q41-q42 cytogenetic rearrangements do not appear to have "classic" Fryns syndrome, due to absence of characteristic features such as facial dysmorphology and phalangeal and/or nail hypoplasia (Table I). However, the extent of anueploidy in these cases could be sufficiently large to obscure a Fryns syndrome phenotype. The combined evidence from cytogenetic, FISH, and aCGH studies indicates a critical region at the junction between bands $1 \mathrm{q} 41$ and $1 \mathrm{q} 42.11$, and suggests therein lies a locus for CDH, Fryns syndrome, or a Fryns syndrome phenocopy. Further characterization of several of the 1q41-q42 chromosome rearrangements is underway.

\section{Note Added in Proof}

Other microdeletions detectable by aCGH at $15 \mathrm{q} 26.2$ and $8 \mathrm{p} 23.1$ in patients with phenotypes similar to Fryns syndrome have just been reported (Slavotinck A et al. 2005. J Med Genet 42:730-736).

\section{Acknowledgments}

We thank the families who have generously participated in this research study. We again express our condolences to the family of Twin B and we remain grateful that they were willing to let us share what we learned from their daughter with others. We thank Lisa Shaffer for allowing us to present her aCGH from the SignatureChip, Dr Franklin Blaise for his assistance with the autopsy examination, and Dr Tucker Collins for supporting this work.

Grant sponsor: NIH PO1 "Gene Mutations and Rescue in Human Congenital Diaphragmatic Hernia"; Grant number: HD 39942-03.

\section{References}

Ackerman KG, Herron BJ, Vargas SO, Huang H, Tevosian SG, Kochilas L, Rao C, Pober BR, Babiuk RP, Epstein JA, Greer JJ, Beier DR. Fog2 is required for normal diaphragm and lung development in mice and humans. PLoS Genet 2005;1:e10.

Arnold SR, Debich-Spicer D, Opitz JM, Gilbert-Barness E. Documentation of anomalies not previously described in Fryns syndrome. Am J Med Genet 2003;116A:179-182. [PubMed: 12494439]

Cohn DH, Starman BJ, Blumberg B, Byers PH. Recurrence of lethal osteogenesis imperfecta due to parental mosaicism for a dominant mutation in a human type I collagen gene (COL1A1). Am J Hum Genet 1990;46:591-601. [PubMed: 2309707]

Devriendt K, Deloof E, Moerman P, Legius E, Vanhole C, de Zegher F, Proesmans W, Devlieger H. Diaphragmatic hernia in Denys-Drash syndrome. Am J Med Genet 1995;57:97-101. [PubMed: 7645607] 
Fryns JP. Fryns syndrome: A variable MCA syndrome with diaphragmatic defects, coarse face, and distal limb hypoplasia. J Med Genet 1987;24:271-274. [PubMed: 3585941]

Fryns JP, Moerman F, Goddeeris P, Bossuyt C, Van den Berghe H. A new lethal syndrome with cloudy corneae, diaphragmatic defects and distal limb deformities. Hum Genet 1979;50:65-70. [PubMed: 381161]

Iafrate AJ, Feuk L, Rivera MN, Listewnik ML, Donahoe PK, Qi Y, Scherer SW, Lee C. Detection of large-scale variation in the human genome. Nat Genet 2004;36:949-951. [PubMed: 15286789]

Kershisnik MM, Craven CM, Jung AL, Carey JC, Knisely AS. Osteochondrodysplasia in Fryns syndrome. Am J Dis Child 1991;145:656-660. [PubMed: 1903587]

Kirchhoff M, Rose H, Lundsteen C. High resolution comparative genomic hybridisation in clinical cytogenetics. J Med Genet 2001;38:740-744. [PubMed: 11694545]

Le Caignec C, Boceno M, Saugier-Veber P, Jacquemont S, Joubert M, David A, Frebourg T, Rival JM. Detection of genomic imbalances by array based comparative genomic hybridisation in fetuses with multiple malformations. J Med Genet 2005;42:121-128. [PubMed: 15689449]

Lin AE, Pober BR, Mullen MP, Slavotinek AM. Cardiovascular malformations in Fryns Syndrome: Is there a pathogenic role for Neural Crest cells? Am J Med Genet. 2005 In press.

Liu J, Zhang L, Wang D, Shen H, Jiang M, Mei P, Hayden PS, Sedor JR, Hu H. Congenital diaphragmatic hernia, kidney agenesis and cardiac defects associated with Slit3-deficiency in mice. Mech Dev 2003;120:1059-1070. [PubMed: 14550534]

Lu MC, Sammel MD, Cleveland RH, Ryan LM, Holmes LB. Digit effects produced by prenatal exposure to antiepileptic drugs. Teratology 2000;61:277-283. [PubMed: 10716746]

Lynch SA, Gaunt ML, Minford AM. Campomelic dysplasia: Evidence of autosomal dominant inheritance. J Med Genet 1993;30:683-686. [PubMed: 8411055]

Meinecke P, Fryns JP. The Fryns syndrome: Diaphragmatic defects, craniofacial dysmorphism, and distal digital hypoplasia. Further evidence for autosomal recessive inheritance. Clin Genet 1985;28:516520. [PubMed: 4075561]

Moerman P, Fryns JP, Vandenberghe K, Devlieger H, Lauweryns JM. The syndrome of diaphragmatic hernia, abnormal face and distal limb anomalies (Fryns syndrome): Report of two sibs with further delineation of this multiple congenital anomaly (MCA) syndrome. Am J Med Genet 1988;31:805814. [PubMed: 3239572]

Petrella R, Rabinowitz JG, Steinmann B, Hirschhorn K. Long-term follow-up of two sibs with Larsen syndrome possibly due to parental germ-line mosaicism. Am J Med Genet 1993;47:187-197. [PubMed: 8213905]

Pober BR, Lin A, Russell M, Ackerman KG, Chakravorty S, Strauss B, Westgate MN, Wilson J, Donahoe PK, Holmes LB. Infants with Bochdalek diaphragmatic hernia: Sibling precurrence and monozygotic twin discordance in a hospital-based malformation surveillance program. Am J Med Genet 2005;138A(Part A):81-88. [PubMed: 16094667]

Ramsing M, Gillessen-Kaesbach G, Holzgreve W, Fritz B, Rehder H. Variability in the phenotypic expression of Fryns syndrome: A report of two sibships. Am J Med Genet 2000;95:415-424. [PubMed: 11146459]

Reardon, W.; Smith, S.; Suri, M.; Grant, J.; O'Neill, D.; Kelehan, D.; Fitzpatrick, D.; Hastie, ND. WT1 mutation is a cause of congenital diaphragmatic hernia associated with Meacham syndrome.

Presented at the annual meeting of the American Society of Human Genetics; October 2000; Toronto, Ontario, Canada. 2004. 2004

Robert E, Kallen B, Harris J. The epidemiology of diaphragmatic hernia. Eur J Epidemiol 1997;13:665673. [PubMed: 9324213]

Rogers JC, Harris DJ, Pasztor LM. Interstitial deletion of the long arm of chromosome 1: del(1)(pter $\rightarrow$ 42.11(x02237)q42.3 $\rightarrow$ qter). Am J Hum Genet 1995;57:A125.

Schwyzer U, Briner J, Schinzel A. Fryns syndrome in a girl born to consanguineous parents. Acta Paediatr Scand 1987;76:167-171. [PubMed: 3564997]

Sebat J, Lakshmi B, Troge J, Alexander J, Young J, Lundin P, Maner S, Massa H, Walker M, Chi M, Navin N, Lucito R, Healy J, Hicks J, Ye K, Reiner A, Gilliam TC, Trask B, Patterson N, Zetterberg A, Wigler M. Large-scale copy number polymorphism in the human genome. Science 2004;305:525528. [PubMed: 15273396] 
Shaw-Smith C, Redon R, Rickman L, Rio M, Willatt L, Fiegler H, Firth H, Sanlaville D, Winter R, Colleaux L, Bobrow M, Carter NP. Microarray based comparative genomic hybridisation (array$\mathrm{CGH}$ ) detects submicroscopic chromosomal deletions and duplications in patients with learning disability/mental retardation and dysmorphic features. J Med Genet 2004;41:241-248. [PubMed: 15060094]

Slavotinek AM. Fryns syndrome: a review of the phenotype and diagnostic guidelines. Am J Med Genet 2004;124A:427-433. [PubMed: 14735597]

Slavotinek AM. The genetics of congenital diaphragmatic hernia. Semin Perinatol 2005;29:77-85. [PubMed: 16050525]

Slavotinek, AM.; Davis, R.; Leeth, E.; Keller, RL.; Nobuhara, KK. Detection of submicroscopic chromosome aberrations and DNA sequence variants in congenital diaphragmatic hernia patients using array comparative genomic hybridization. 26th Annual DW Smith Workshop; August 2-5, 2005; 2005a.

Slavotinek AM, Robinson H, Steele MA. Fryns syndrome with osteochondrodysplasia. Am J Med Genet 2005b;134A:454-456.

Smith SA, Martin KE, Dodd KL, Young ID. Severe microphthalmia, diaphragmatic hernia and Fallot's tetralogy associated with a chromosome 1;15 translocation. Clin Dysmorphol 1994;3:287-291. [PubMed: 7894732]

Tibboel D, Gaag AV. Etiologic and genetic factors in congenital diaphragmatic hernia. Clin Perinatol 1996;23:689-699. [PubMed: 8982564]

Tonks A, Wyldes M, Somerset DA, Dent K, Abhyankar A, Bagchi I, Lander A, Roberts E, Kilby MD. Congenital malformations of the diaphragm: Findings of the West Midlands Congenital Anomaly Register 1995-2000. Prenat Diagn 2004;24:596-604. [PubMed: 15305345]

Torfs CP, Curry CJ, Bateson TF, Honore LH. A population-based study of congenital diaphragmatic hernia. Teratology 1992;46:555-565. [PubMed: 1290156]

Tsukahara M, Sase M, Tateishi H, Saito T, Kato H, Furukawa S. Skeletal manifestations in Fryns syndrome. Am J Med Genet 1995;55:217-220. [PubMed: 7717421]

Vissers LE, van Ravenswaaij CM, Admiraal R, Hurst JA, de Vries BB, Janssen IM, van der Vliet WA, Huys EH, de Jong PJ, Hamel BC, Schoenmakers EF, Brunner HG, Veltman JA, van Kessel AG. Mutations in a new member of the chromodomain gene family cause CHARGE syndrome. Nat Genet 2004;36:955-957. [PubMed: 15300250]

Youssoufian H, Chance P, Tuck-Muller CM, Jabs EW. Association of a new chromosomal deletion [del (1)(q32q42)] with diaphragmatic hernia: Assignment of a human ferritin gene. Hum Genet 1988;78:267-270. [PubMed: 3162227]

Yuan W, Rao Y, Babiuk RP, Greer JJ, Wu JY, Ornitz DM. A genetic model for a central (septum transversum) congenital diaphragmatic hernia in mice lacking Slit3. Proc Natl Acad Sci USA 2003;100:5217-5222. [PubMed: 12702769] 

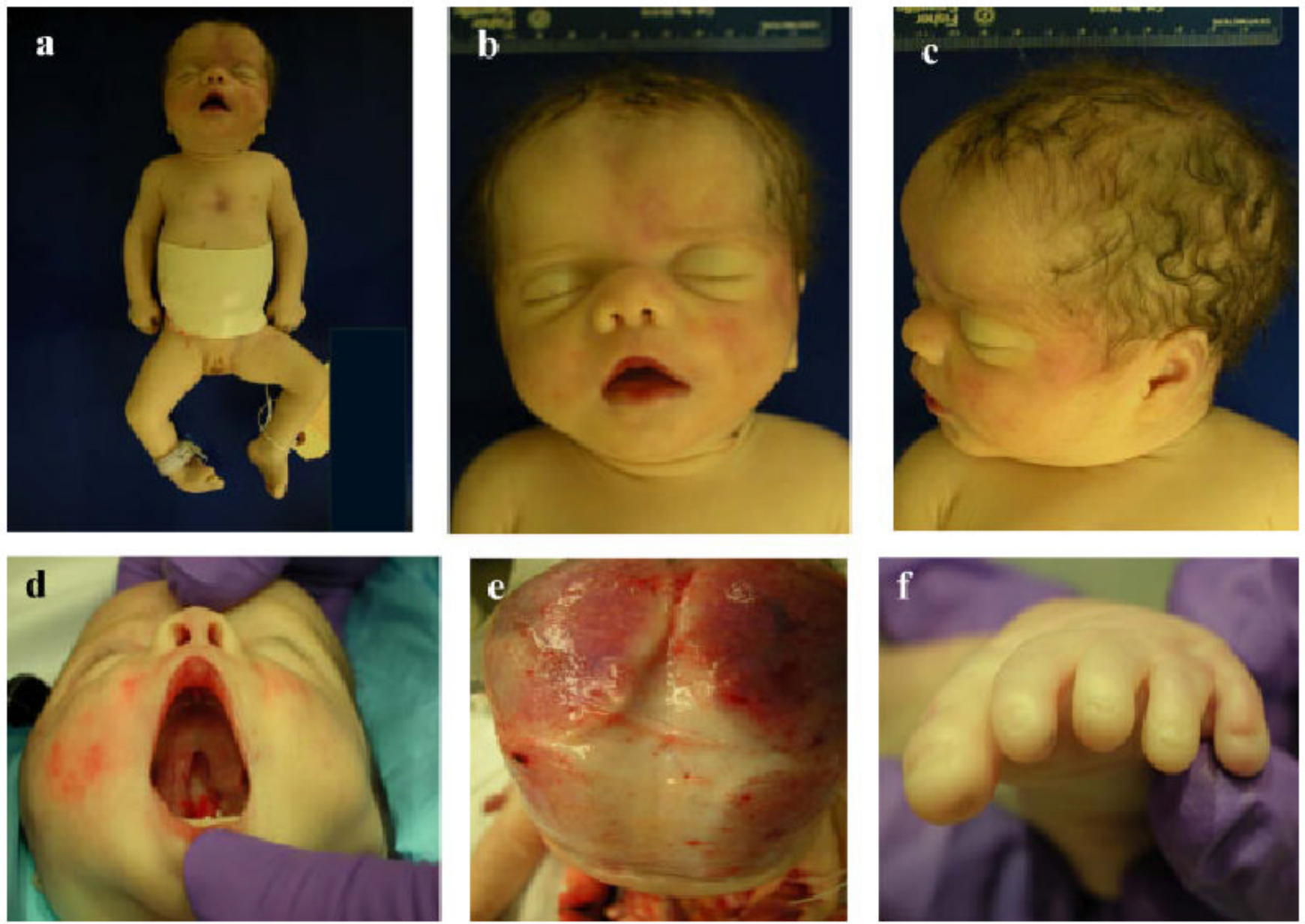

Fig. 1.

Photographs taken during post-mortem examination of Twin B. a: Full body view shows dysmorphic features, mild proximal rhizomelic shortening, right club foot. Bandage across abdomen is secondary to emergency evacuation of hemoperitoneum; b: Close-up of face shows mildly coarse features, boxy forehead, depressed nasal bridge, full nasal tip, infra-orbital creases; c: Lateral view of face shows the distinctive features noted in panel b; d: View of palate shows cleft of posterior soft palate; e: View of skull following removal of scalp-infant is facing forward and large anterior fontanelle is seen. Similarly large posterior fontanelle is not captured in this image; $\mathbf{f}$ : View of foot-Moderate toenail hypoplasia is seen. Photographs of fingernails were of poor quality but examination demonstrated nail hypoplasia in the transverse diameter. The fingernials and toenails in Twin B were smaller than those found in her phenotypically normal cotwin (Twin A). 

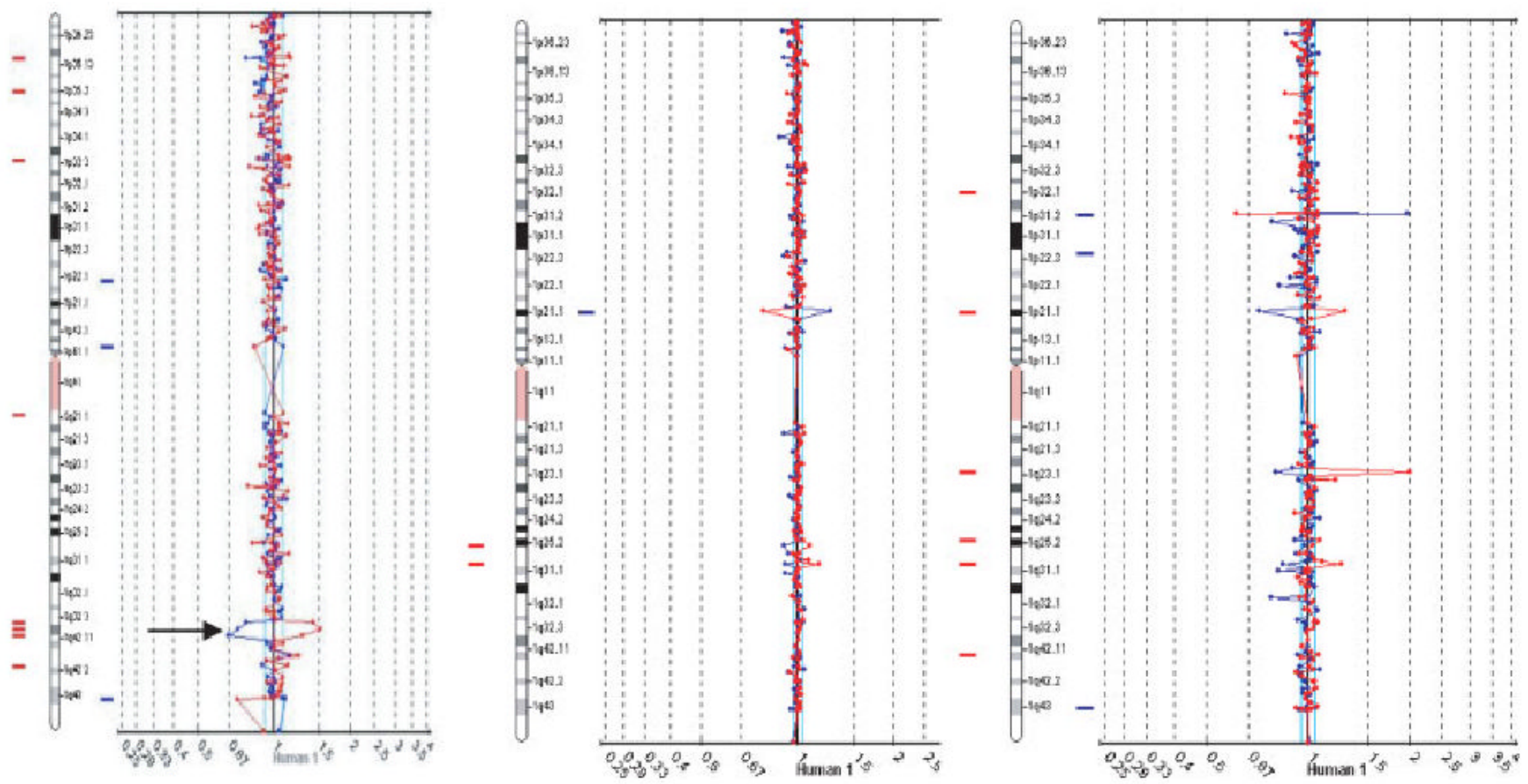

Fig. 2.

Spectral Chip $2600^{\mathrm{TM}}$ aCGH results. a: Results from Spectral Chip $2600^{\mathrm{TM}} \mathrm{aCGH}$ in proband with the clinical diagnosis of Fryns syndrome. Deletion of three consecutive BAC clones RP11-124J24 (1q41), RP11-239E10 (1q41 - 1q42.11), and RP5-1090A23 (1q42.12) is marked by an arrow; b: Normal aCGH results on proband's mother; c: Normal aCGH results on proband's father. 
Fig. 3.

FISH results confirming del (1)(q41q42.12): Only a single copy of RP11-124J24 (green) mapping to $1 \mathrm{q} 41$ is demonstrated in the proband. Both copies of the control probe DXZ1 (red) mapping to the chromosome 1 centromere region are visible. 


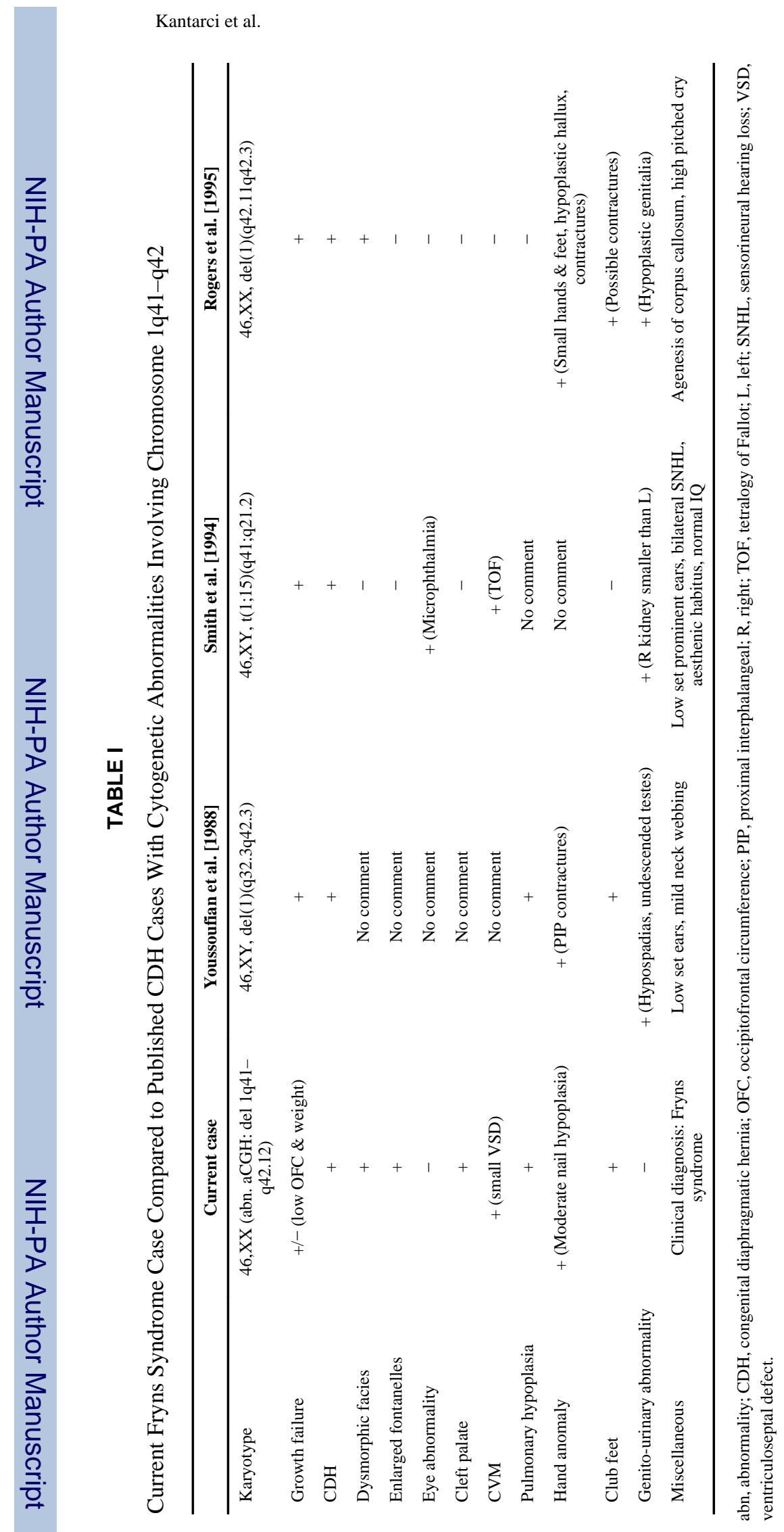

Am J Med Genet A. Author manuscript; available in PMC 2010 June 24. 